\title{
Use of Acoustic Emission in the Evaluation of Corrosion Resistance of CMT Welds
}

Jakub Rozlivka, Michal Šustr, Václav Kašpar

Faculty of Technology and Automobile Transport, Mendel University in Brno. Zemědělská 1, 61300 Brno. Czech Republic.E-mail: xrozlivk@mendelu.cz,michal.sustr@mendelu.cz, xkaspar@mendelu.cz

The objective of this paper was to investigate and respond to the quality and strength of CMT welds that were subjected to degradation effects and subsequently to tensile testing. The tensile test was recorded using AE acoustic emission. The experiment focused on the quality of CMT welds (Cold Metal Transfer) and the resistance of these welds to corrosion degradation. Welds are generally exposed to environmental influences such as high stress, stress and degradation effects. The combined effect of these factors may in some cases result in the destruction of weld joints. For this reason, emphasis is placed on the quality of welds and their resistance to environmental influences. For this measurement there were ten samples prepared, divided into two groups, each having five samples. One group was subjected to corrosion degradation, while the other one was at the same time subjected only to environmental influences. Subsequently, all samples were subjected to tensile testing. The course of this test was recorded using the $\mathrm{AE}$ acoustic emission, where the $\mathrm{AE}$ sensor was attached to each weldment to record dislocations during the tensile test. Named values were evaluated in the Dakel-Daeshow program.

Keywords: Acoustic emission, Bending, Corrosion resistance, Diagnostics

\section{Introduction}

Requirements for high welding productivity of soldering and, at the same time, the quality of the joints cause an effort to limit the influence of the human factor. An example of great progress in welding technology is the so-called CMT process (Cold Metal

a)

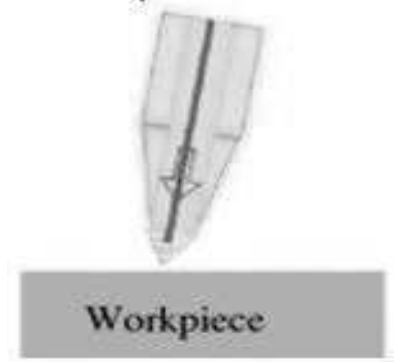

b)

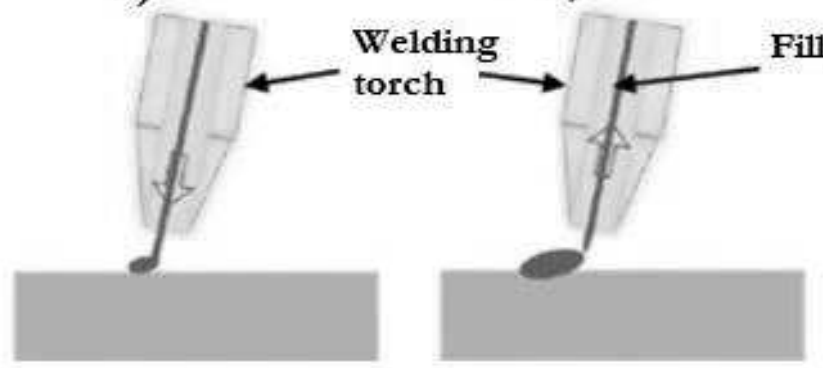

Fig. 1 Welding process by $C M$
Transfer) which, in addition to other application areas, allows steel and aluminum material to be connected by an electric arc. This is basically the MIG/MAG process that works, unlike other common processes, with very low heat inputs. This technique is based on the use of the drop release method using the alternating forward and reverse motion of the wire, see Figure 1 [6].

c)

d)

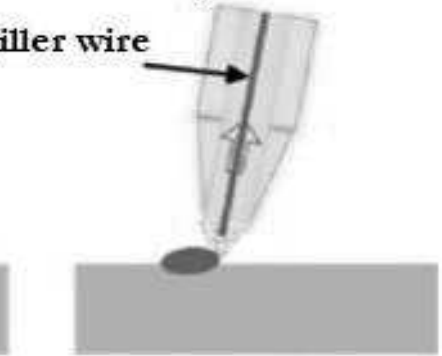

Where:

a)...During the burning phase of the arc, additional is fed into the melt bath (Figure 1a),

b)...When the additional material is burned in the melting bath, the arc goes off, the welding current drps sharpply (Figure 1b),

c)...The return motion of the wire support a droplet release during a short circuit, the short-circuit current is kept low (Figure 1c),

d)... The direction of wire movement is reversed and the process starts again (Figure 1d).
CMT welding with a protective electrode smelting combines the hot phase of the arc burning when the wire and the base material are melted with the cold part of the process, where the contact of the melted wire with the melting bath reduces the current intensity and the wire returns back to the nozzle.

This facilitates the separation of droplets without spraying and low heat input into the weld. The whole process is digitally controlled, and nowadays the backward motion of the wire takes place up to 130 times per second. 
CMT makes it possible to ensure the requirement for low thermal load, good bridge crossing and minimal thermal deformation, especially when joining aluminum and stainless steels to eliminate the need for subsequent machining The requirements of the welding industry are increasing, especially in the field of thermal bonding to thin sheet metal (up to $2 \mathrm{~mm}$ ) [6]

Samples were made on ten furnaces of the following materials. For the aluminum welding part, aluminum blank AlMg3 was used for blank blank CSN 424413 [14] - chemical composition: $\mathrm{Mg}-4,0, \mathrm{Mn}-$ $0,4, \mathrm{Si}-0,5, \mathrm{Fe}-0,4, \mathrm{Ti}-0,2, \mathrm{Zn}-0,2, \mathrm{Cu}-0,1, \mathrm{Cr}$ $-0,05, \mathrm{Fe}+\mathrm{Si}-0,6$ and their mechanical properties: $\mathrm{Rm}-19-240$ [MPa], Re - 80 [MPa], A - 17 [\%]. The steel part of the sample used the metallurgical plate ČSN EN 10143 (420036) (ÚNMZ 1997), steel sheets hot galvanized. The AlSi5 additive was used as an ingredient - chemical composition: $\mathrm{Si}-4,7, \mathrm{Mn}-0,01$, $\mathrm{Ti}-0,01, \mathrm{Fe}-0,3, \mathrm{Zn}-0,01$ an their mechanical properties of joint: Rm - 140 [MPa], Re - 50 [MPa], A $10-17[\%]$.

One group of five samples was subjected to corrosition testing in a Liebisch-type $\mathrm{NaCl}$ degradation chamber S 1000 M-TR. These corrosion tests were carried out in compliance with ISO 9227. A corrosive environment in the form of a salt mist (sodium chloride atmosphere) of $50 \pm 5 \mathrm{~g} / \mathrm{l}$ of distilled water was used for accelerated corrosion tests. The density of the solution at this concentration and at $25{ }^{\circ} \mathrm{C}$ is 1.0225 to $1.0400 \mathrm{~g} \mathrm{~cm}^{3}$. Corrosion tests are carried out at 35 ${ }^{\circ} \mathrm{C}$. In general, this corrosion test can be used for metals, their alloys, metal coatings or organic coatings on metal substrates $[5,9,11]$. In this environment has been create on the samples galvanic corrosion. Galvanic corrosion is a effect of macro-elements is the intensification of the corrosion on the surface of the metal that is present anodic conditions and, on the contrary, metal corrosion at cathodic sites is a link to an article usually limited. The action of an article is triggered by either diversity linked, electrically conductive,

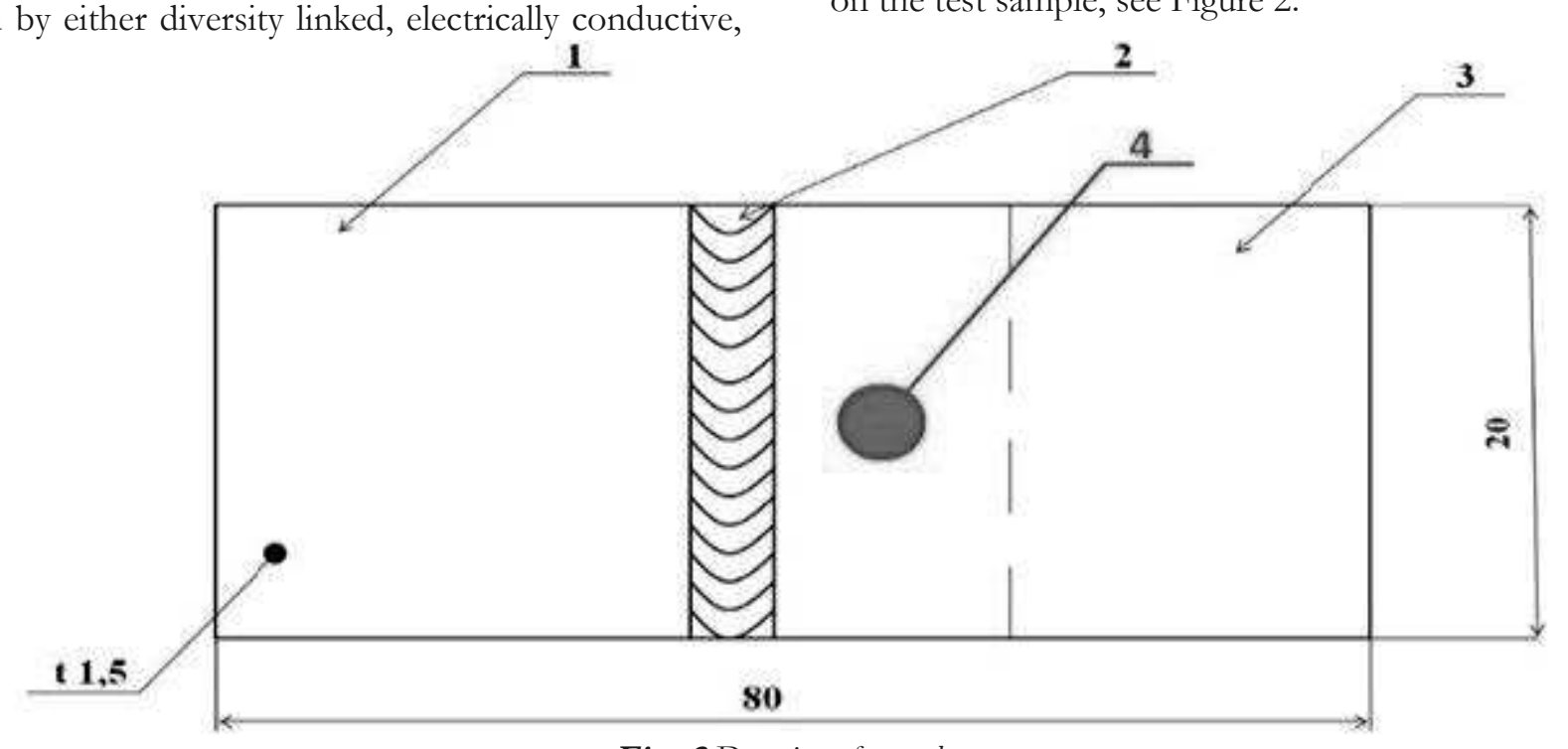

Fig. 2 Drawing of samples material, or heterogeneity of the composition of the environment, its temperature or flow. Heterogeneity in the composition of the surface adjacent to the metal surface need not be given only starting conditions, but can only occur as a result of corrosion processes (formation of occluded solutions) $[1,10,11]$.

In the next step, all ten samples were subjected to tensile testing according to CSN EN ISO 6892-1 (420310) [7, 13], which is the basic test used to verify the strength and plastic properties of the material. The test consists in deforming the test rod by uniaxial tensile loading usually in the rupture to determine one or more of the stress and strain characteristics introduced in the standard. Unless otherwise stated, it is tested at ambient temperatures in the range between $10{ }^{\circ} \mathrm{C}$ and $35^{\circ} \mathrm{C}$. For this test, an AE sensor, type MTR15/MTPA-15, was added to each sample, see Figure 3 . The applied acoustic sensor recorded emerging dislocations within the material $[2,12]$.

\section{Material and methods}

Ten welds were made; the weldments were divided into two groups of five. The first group was subjected to degradation conditions in the saline nebula in the Liebisch-type $\mathrm{NaCl}$ degradation chamber S $1000 \mathrm{M}-$ TR. Samples were left for 1000 hours. During this exposure, samples were monitored and recorded for the rate of galvanic corrosion. The second group of five samples was left only by environmental influences. At the end of the experiment, samples were analyzed for corrosion degradation of the weld by tensile tests [3, 4]. All samples were then subjected to pull testing. The course of these tests was recorded on the Dakel-Xedo measuring device. The ZDM 5/51 test machine was designed to test the overall strength of the damaged degradation. The test sample was clamped into the jaws (upper and lower). After clamping the jaw speed was set and a piezoelectric AE sensor was mounted on the test sample, see Figure 2.

Fig. 2 Drawing of samples 
Where:

1...AlSi5,

2...Auminium alloy AlMg3,

3...Base materiál,

4...Sensor of the MTR-15/MTPA-15 type.

This sensor was fixed at the top of the tensile test by means of a spring clamp. The contact surface of the sensor was coated with a special sonographic gel for optimal transfer of the acoustic signal from the sample to the sensor. By activating the starter on the PC, the jaws of the test machine started to move. Subsequently, the sample was subjected to uniaxial tensile stress.
Using a special M-TEST program, the final strength and time of sample breakdown was determined. This procedure was the same as for the corrosion-degraded samples where the corrosion layer was removed in place of the sensor picker, as well as for the samples not subjected to the degradation effects.

Figure 5 clearly shows that during the tensile test the deformation of the material occurs primarily in the area of the base material (No. 3). It is primarily the area affected by the welding process (about $1.5 \mathrm{~mm}$ from the weld).

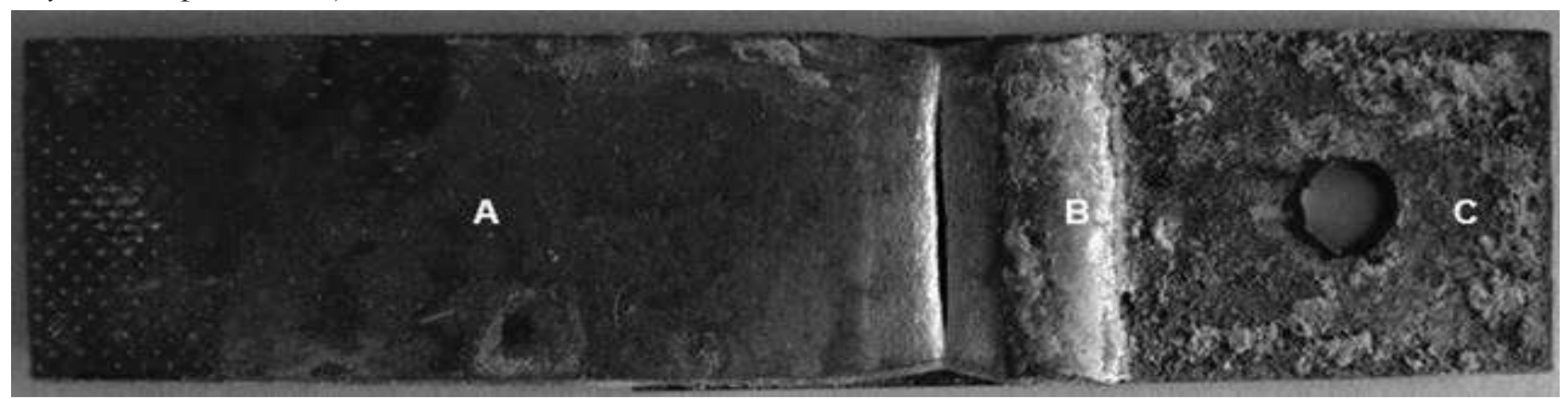

Fig. 3 Sample after corrosion degradation

Where:

A...Aluminium alloy AlMg3,

B...Weld joint,

C...Base materiál (steel),

\section{Result and discussion}

Based on the values obtained after testing all the samples on the universal test machine ZDM 5/51, a table was produced. This table contains the measured maximum force values obtained during the tensile test for the individual test specimens, see Table 1.

For the purposes of further evaluation of the measured data in this work, graphs from the AE measurement were used for representative samples No. 3, see Figures 4 and 5.

Tab. 1 Overview of achieved maximum forces during the tensile test

\begin{tabular}{c|c|c|c}
\multicolumn{2}{c|}{ Non-corroded samples } & \multicolumn{2}{c}{ Corroded samples } \\
\hline Sample Number & $F_{\max }[\mathrm{N}]$ & Sample Number & $F_{\max }[\mathrm{N}]$ \\
\hline 1 & 2452 & 1 & 2096 \\
2 & 2144 & 2 & 1913 \\
$\mathbf{3}$ & $\mathbf{2 3 0 0}$ & $\mathbf{3}$ & $\mathbf{2 0 2 0}$ \\
4 & 2215 & 4 & 2078 \\
5 & 2387 & 5 & 1852 \\
\hline
\end{tabular}

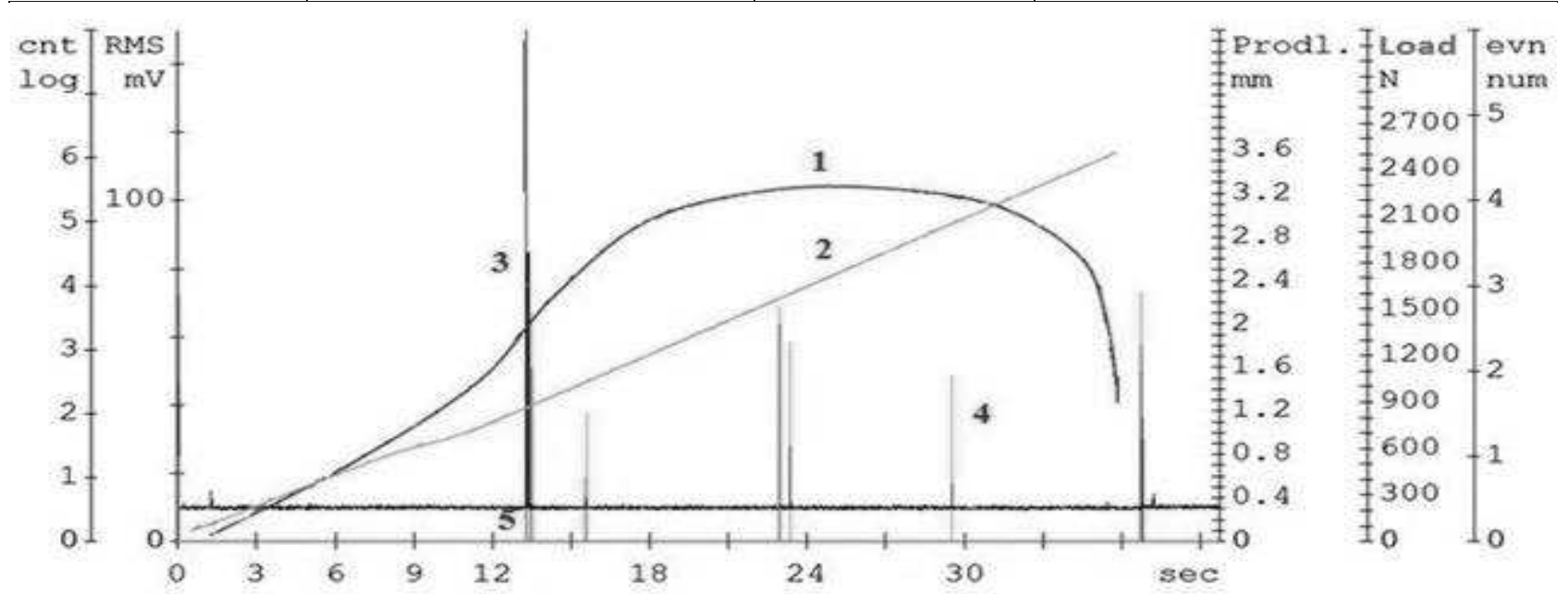

Fig. 4 The acoustic emission signal for the non-corroded sample is related to its extension 
Where:

1....Load,

2...Strain,

3... RMS signal,

4... Count $^{1}$,

5.... Count $^{2}$.

The recording of the acoustic emission in relation to the load and extension of the test sample. In Figure 4, the AE activity is evident in correlation with the change in loading force and elongation in the uncorrelated test sample. During the tensile test, a maximum loading force of $2300 \mathrm{~N}$ was achieved. The graph also shows that the elongation of the sample was almost constant during the experiment. During a $1300 \mathrm{~N}$ load, a strong AE event occurred indicating that the yield strength of the sample was exceeded. When this limit is exceeded, irreversible deformation of the sample occurs.

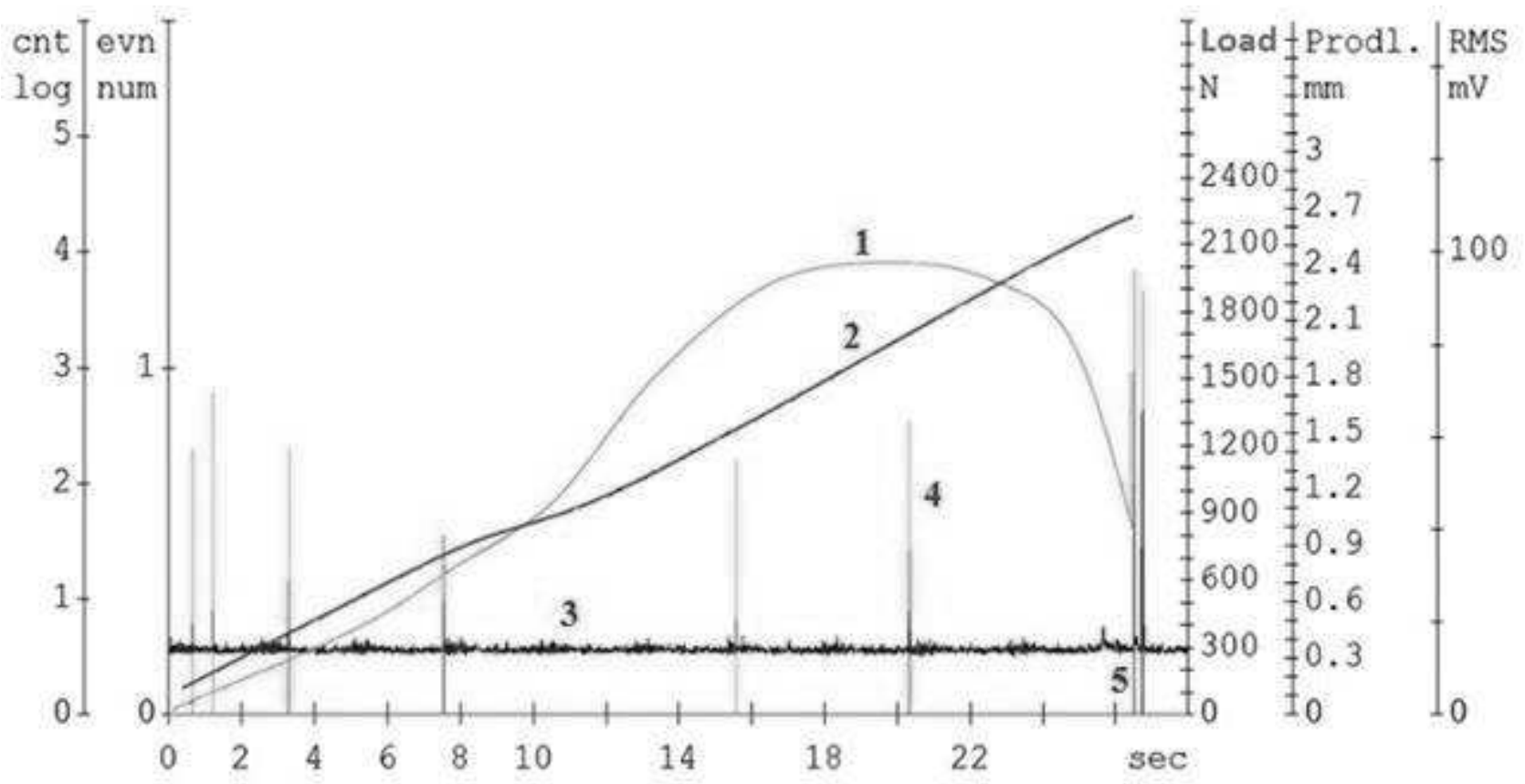

Fig. 5 The acoustic emission signal for the corroded sample is related to its extension

Where:

1...Load,

2...Strain,

3... RMS signal,

4.... Count $^{1}$,

5.... Count ${ }^{2}$.

For samples subjected to aggressive media, Table 1 shows a decrease in the maximum achieved forces. It is clear from Figure 5 that a maximum force of 2020 $\mathrm{N}$ has been reached in this case. Some ellipses may be indicated from the elongation curve. After 1000 hours of accelerated corrosion testing, the material is already degraded by galvanic corrosion at the site of the interaction of materials, with a significant reduction in cohesion. In this case, the formation of major cracks and material discontinuities caused by this stress is eliminated during tensile stress. All deformations are thus absorbed by microcracks at corrosion pits and dots. No significant AE events occurred during this measurement [8].

In the uncorrected sample, the tensile strength of the weld was as high as $348 \mathrm{MPa}$. Samples subjected to the corrosion test achieved lower tensile strengths than those not exposed to corrosion tests. these samples did not exceed $85 \mathrm{MPa}$.

\section{Conclusion}

The AE measurement is used to track especially localized types of corrosion. The authenticity of the AE measurement results is not affected by the heterogeneity of the working environment parameters, which is the building requirement of the plant. The advantage of corrosion monitoring by AE measurement is an easy way to determine the location of the $\mathrm{AE}$ source location - the location of the corrosion damage site. The tests demonstrate useful applications of the AE methods in the field of galvanic corrosion detection and show possible use of AE. This is mainly the continuous monitoring of galvanic corrosion and the reporting of incoming risks in the area of component safety.

The second part of the experiment describes the measurement of AE in tensile stress in CMT welding samples. Some of these samples were exposed to a highly aggressive environment and then compared with samples exposed only in the environment of one 
of the laboratories. All samples subjected to degradation tests showed a lower load bearing capacity than the samples kept in a neutral environment. During the stress test on neutral samples, a maximum loading force of $2300 \mathrm{~N}$ was achieved. The graphs also show that the sample extension was almost constant during the experiment. In contrast, samples subject to an aggressive environment (saline chamber) show a noticeable reduction in maximum strength. It is clear from the $2^{\text {nd }}$ graph that in this case the maximum force of $\mathrm{N} 2$ was reached. Some ellipses can be marked by elongation of the curve. After 1000 hours of accelerated corrosion testing, the material was damaged by galvanic corrosion at the point of interaction of materials with a significant reduction in cohesion.

The AE measurement has proven the proposed methodology to be useful and has provided insight into the behavior of $\mathrm{AE}$ sources in the material during stress testing. It is evident that the corrosion degradation of the surface of the samples in the degradation chamber affected the sources themselves, so there were no significant AE events. Trailability Trail AE is useful for accurately recognizing unstable areas in samples that are less affected by corrosion degradation.

\section{Acknowledgement}

The research has been supported by the project TP 6/2017: Defectoscopic quality assessment of technical and organic materials; financed by IGA FA MENDELU.

\section{References}

[1] ČERNÝ, M., MAZAL, F., FILÍPEK. J. (2005). Display Voltage and Deformation Using AE. Acta Universitatis Agriculturae et Silviculturae Mendelianae Brunensis, No. 2, pp. 63-74. Available at: https://acta.mendelu.cz/media/pdf/actaun_2005053020063.pdf. Czech.

[2] DAKEL. (1989). Collective farm Rpety based in Rpetech Technical Diagnostic Center - DAKEL. Availabel at: http://www.dakel.cz/index.php?pg=about.

[3] DOSTÁL, P., COMMUNEAU, P. (2014). Visualisation of Corrosion Acoustic Signals Using Quality Tools. Acta Universitatis Agriculturae et Silviculturae Mendelianae Brunensis, No. 1, pp. 6569. Available at: https://acta.men delu.cz/media/pdf/actaun_2014062010065.pdf. Czech.

[4] DOSTÁL. P., KUMBÁR. V., ČERNÝ. M., SABALIAUSKAS. A. (2012). Accelerated Corrosion and Fatigue Monitoring of Aluminium Alloy EN AW 7075. Jauniju Mokslininku Darbai, No. 5, pp. 112-118. Available at: http://www.su.lt/bylos/mokslo_leidiniai/jmd/2012_5_38/dostal_kumbar_cerny_sabaliauskas.pdf. Lithuania.

[5] DOBROCKY, D., JOSKA, Z., STUDENY, Z., POKORNY, Z., SVOBODA, E. (2020). Quality Evaluation of Carburized Surface of Steel Used in Military Technology. In: Manufacturing Technology, Vol. 20, 2020, No. 2, p. 152161. ISSSN: 1213-2489.

[6] FRONIUS. (2018). Fronius welding processes. Available at: https://www.fronius.com/cscz/czech-republic/perfect-welding/o-svarovani/svarovaci-procesy. Czech.

[7] KOPEC, B. (2008). Non-destructive testing of materials and structures (material science). $1^{\text {st }} \mathrm{ed}$. Academic publishing house CERM. Brno.

[8] KREIDL, M., ŠMÍD, R. (2006). Tecbnical diagnostics - sensors, methods, signal analysis - 4th part of edition Sensors of non-electrical quantities. $1^{\text {st }}$ ed., BEN - technical literature. Prague.

[9] LASEK, S. (2014). Basics of degradation processes: study support. $1^{\text {st }}$ ed., Ostrava: VŠB - Technical University of Ostrava. Ostrava.

[10] MILLER, K.R. (2005). Nondestructive Testing Handbook: Acoustic Emission Testing. $3^{\text {rd }}$ ed., USA: Amer Society for Nondestructive Testing. USA.

[11] Votava, J., KumbáR, V., DOstÁL, P. (2014). Degradation processes of Al-Zn welded joints. Acta Universitatis Agriculturae et Silviculturae Mendelianae Brunensis, No. 3, pp. 571578. Available at: https://acta.mendelu.cz/media/pdf/actaun_2014062030571.pdf. Czech.

[12] SOLFRONK, P., SOBOTKA, J., KORECEK, D. (2020). Utizilation of Advance Computation Methods to Predict Spring-back of Aluminium Alloys in Automotive. In: Manufactoring Technology, Vol. 20, 2020, No. 1, p. 98-103. ISSN: 1213-2489.

[13] ÚNMZ. (2017). Metallic materials - Tensile testingPART 1: Test method at room temperature. CSN EN ISO 6892-1 (420310). Office for Standards, Metrology and Testing. Prague.

[14] ÚNMZ. (1981). Wrought aluminum alloy 424413. ČSN 424413 (424413). Office for Standards, Metrology and Testing. Prague.

[15] ÚNMZ. (1997). Continuously hot-dip coated steel sheets and strips - Dimensional tolerances and shape tolerances. CSN EN 10143 (420036). Office for Standards, Metrology and Testing. Prague. 